\title{
HERNANDO DE ACUÑA: SU POÉTICA Y SU «SABROSA HISTORIA DEL ALMA»
}

\author{
RUSSELl P. SEBOLD \\ Académico correspondiente \\ de la Real Academia Española
}

\section{RESUMEN}

Poeta de la soledad en medio de la guerra, Hernando de Acuña pertenece a la primera generación de emuladores de esa «regla cierta» que caracterizó a la obra del clásico español Garcilaso de la Vega. En la locución de Acuña se destaca ese feliz maridaje de la llaneza del lenguaje popular y la sencillez del clasicismo depurado que es el sello de la literatura quinientista española. Lo más notable del estilo individual de Acuña es un fecundo juego entre la llaneza y el sentimiento de lo sublime; sobre su estilo el poeta reflexiona en sus poemas. Acuña concibe el conjunto de su obra poética como la historia de su alma. Por el contenido de ésta se revela la extraordinaria simpatía del poeta soldado, y por la estructura de su historia se descubre su insospechado talento de narrador. El orden que dio a sus poemas es instrumental para su veta narrativa.

Palabras clave: soledad, clásico, neoclásico, Garcilaso, poética, llano, bajo, sublime, cuento, verso autónomo, narrador.

\begin{abstract}
Poet of solitude in the nidst of war, Hernando de Acuña belongs to the first generation of neoclassical emulators of that «certain rule» that characterized the work of the Spanish classic Garcilaso de la Vega. Acuña's locution is marked by that happy marriage of the plainness of popular language and the simplicity of polished classicism that is the hallmark of fifteenth-century Spanish literature. Most notable in Acuña's individual style is a fruitful interplay between plainness and the feeling of the sublime; the poet reflects on his style in his poems. Acuña conceives the whole of his poetic work as the history of his soul. Through the content of the latter the extraordinary sympathy of the poet soldier is revealed, and through the structure of his history one discovers his unsuspected talent as a narrator. The order that he gave his poems is instrumental for their narrative vein.
\end{abstract}

Key words: solitude, classical, neoclassical, Garcilaso, poetics, plain, low, sublime, story, autonomoous verse, narrator.

«Pues se conforma nuestra compañía, / no dejes, soledad, de acompañarme - le implora insistente a su aérea compañera el poeta Hernando de Acuña (1518-¿1580?)—, / que al punto que vinieses a faltarme / muy mayor 
soledad padecería» ${ }^{1}$. En los mismos versos, el poeta le encarece a la soledad los encantos que descubre en su compañía: «Tú haces ocupar mi fantasía / sólo en el bien que basta a contentarme». ¿Cuál es el fruto de fantasía tan feliz como ocupada, y cómo pagará el poeta los favores de una compañera tan conforme a su gusto?

Responde así Acuña, en el precioso Soneto a la soledad que venimos citando: «Contigo partiré, si no me dejas, / los altos bienes de mi pensamiento». Añade una condición que no acata casi ningún poeta, ni mucho menos los simples mortales, en sus horas dedicadas a la soledad: «y no te daré parte de mis quejas». Uno de los grandes atractivos de este soneto, que parecerá contemporáneo al lector de cualquier siglo en que haya todavía poesía, es la elegante llaneza de su expresión. Con su vaporosa compañera de las horas desiertas Acuña gasta el mismo lenguaje sencillo que con su Silvia o con su Galatea, rehuyendo las más de las veces ese frío estilo seudo-escolástico por el que se dejan llevar no pocos poetas petrarquistas.

No hacen falta más testimonios para asegurarnos de que Hernando de Acuña es un hombre de una enorme sensibilidad poética; pues la relación que él tiene con la soledad es la que tiene con ella todo poeta auténtico. Pero miremos más detenidamente el ya aludido fruto de sus diálogos con la soledad: el pensamiento. En el primer cuarteto de su soneto LXXVII, nuestro poeta vallisoletano reflexiona sobre los ya mencionados consuelos de su pensamiento: «Del bien del pensamiento se sustenta / el triste corazón entre mil males, / que en mí se tratan como naturales» (311). Prodúcese en este poeta una repetida dialéctica entre la consolación y la aflicción, según se desprende asimismo de los primeros versos del soneto LXXXII: «En medio del placer que el pensamiento / me causa con mostrárseme presente, / Amor, que por ser bien no lo consiente, / le vuelve por usanza al mal que siento» (314).

Más significativo para nuestro tema, empero, es el placer que le trae al poeta el pensamiento en sí, o simplemente por su presencia. En su correspondencia poética con su amado amigo Boscán, Garcilaso de la Vega buscaba el placer de «daros cuenta de los pensamientos, / hasta las cosas que no tienen nombre» ${ }^{2}$. Esto es, lo inefable, inspiración tantas veces de la poesía. Al mismo tiempo, pensamiento, entre sus varias acepciones, es la idea inicial o germen de una obra. Ejemplo de cuya acepción tenemos en la descripción de Galatea en otro soneto de Acuña: «...que natura / jamás se satisfizo sino en ella, / y aquí pasó del pensamiento el arte» (308).

Soledad y pensamiento dan nacimiento a la poesía, así como a fecun-

${ }^{1}$ HeRnANDo DE ACUÑA, Varias poesías, ed. de Luis F. Díaz Larios, Letras Hispánicas, 164, Madrid, Cátedra, 1982, p. 305. Las siguientes referencias a esta edición se insertarán en el texto, en esta forma: (305).

${ }^{2}$ Garcilaso DE La VeGa, Obra poética y textos en prosa, ed. de Bienvenido Morros, Biblioteca Clásica, 27, Barcelona, Crítica, 1995, p. 115. 
das reflexiones en torno al arte del verso. Mas el poeta soldado Hernando de Acuña reflexiona asimismo sobre su otro arte de las armas, y entre uno y otro no conoce nunca esa melancólica «mayor soledad» que sufriría si le abandonara la soledad. Habla al parecer con uno de sus comandantes, muy posiblemente Alfonso de Ávalos, marqués del Vasto, también poeta:

Así sus horas con la espada a Marte,

y los ratos del ocio con la pluma

pienso, señor, enderezar a Apolo;

dando a los dos de mí tan larga parte,

y tomándola dellos tal, que en suma

no me cause tristeza el verme solo. $(263)^{3}$

Decía Acuña que el pensamiento le causaba placer, y tan ingeniosos artistas son el pensamiento y la soledad, que hasta el peligro pasado lo pintan como placer: "Yo miro, ya seguro desde el llano, / el risco en que me vi y el paso estrecho, / quedando ya seguro de mis daños» (239).

Pero volvamos a las reflexiones de Acuña sobre la poesía. Sus horas de recogimiento le permiten recorrer todo el campo del oficio apolíneo, desde los admirados modelos poéticos de la antigüedad, hasta otros grandes modelos contemporáneos, como Garcilaso, hasta cuestiones estilísticas y temáticas concretas. Sus traducciones de Ovidio, su tratamiento de temas como Ícaro, Faetón y Endimión y su cultivo de un género poético como la égloga son testimonios de su amor a la tradición poética grecorromana. Su poema La fábula de Narciso, adaptación de La favola di Narciso, de Alamanni, es otra muestra de la misma afición clásica. Mas lo esencial en el tiempo de Acuña es que se va forjando una nueva acepción de este último calificativo, clásico, la cual aparecerá ya con la mayor naturalidad en el célebre Panegírico por la poesía de 1627, cuyo desconocido autor ve como «poetas clásicos» a muchos españoles modernos, especialmente a «los que mejor imitan a Garcilaso» ${ }^{4}$.

En mi libro Lírica y poética en España, 1536-1870, he dicho que al morirse Garcilaso de la Vega se reconoció en él el ideal clásico moderno, y nació sin más el neoclasicismo. «Y aquel que nuestro tiempo trujo ufano, / el nuestro Garcilaso de la Vega», era para su entrañable compañero Juan Boscán una cumbre poética a la que difícilmente se volvería a acceder, sin que se fundara sobre ese recuerdo una nueva escuela de poetas; porque Garcilaso de la Vega, decía el mismo amigo, «no solamente en mi opinión, mas en la de todo el mundo, ha sido tenido por regla

${ }^{3}$ En el primer cuarteto del soneto CIV, Acuña vuelve a este tema: «Jamás pudo quitarme el fiero Marte, / por más que en su ejercicio me ha ocupado, / que en medio de su furia no haya dado / a Apolo de mi tiempo alguna parte» (342).

${ }^{4}$ Panegírico por la poesía, Sevilla, Oficina de D. Enrique Rasco San Román, 1886, fols. 51,53 . 
cierta ${ }^{5}$. Desde aquel momento en adelante los poetas castellanos tuvieron dos nortes, por decirlo así, y ninguno de ellos sería visto ya como competente sin guiarse por esas dos estrellas clásicas: la grecolatina antigua y la española moderna. En mi citado libro, he documentado este nuevo clasicismo de doble origen a lo largo de los siglos, en ninguno de los cuales se sostendría con mayor ánimo y ardor que en el setecientos, cuando se iba a insistir más que nunca antes en el modelo del clasicismo español. En el prólogo a la primera edición de Garcilaso que se había estampado en 107 años, Madrid, Imprenta Real de la Gaceta, 1765, José Nicolás de Azara da la mayor importancia a ambos clasicismos, especialmente al español: «El poeta que no haya imitado a los antiguos, no será imitado de nadie [...]. Garcilaso se hizo poeta estudiando la docta antigüedad [...], y éste es el modelo que presento a mis paisanos» ${ }^{6}$.

Hernando de Acuña es, por lo tanto, un poeta de la primera de las generaciones neoclásicas que Boscán vislumbraba. En 1620, en la Introducción a la Justa poética al bienaventurado San Isidro, Lope de Vega escribiría: «Trabajan mucho algunos por volver al pasado siglo nuestra lengua»? Mas sin necesidad de hacer un esfuerzo tan extraordinario, Acuña se inspira en el sano ambiente de su propia centuria, no solamente en Garcilaso, sino en los abundantes modelos estilísticos sencillos, claros, puros, en una palabra, clásicos, que había en ese más dorado de los tiempos, en el que aún era natural esa «llaneza con grandeza», que el humanista Pedro de Valencia recomendaría en vano al tenebroso segundo Góngora ${ }^{8}$. Mas consideremos la deuda de Acuña con Garcilaso y su fidelidad al espíritu garcilasiano.

El soneto LXIII de Acuña (286), «Cuando contemplo el triste estado mío», se inspira en el Soneto I de Garcilaso, «Cuando me paro a contemplar mi 'stado»"; el soneto LXXXVI de Acuña (317), «iOh celos, mal de cien mil males lleno», está endeudado con el soneto XXXIX de Garcilaso, «iOh celos, de amor terrible freno» ${ }^{10}$; y el poema CII de Acuña, «Si Apolo tanta gracia / en mi rústica cítara pusiese» (336-339), una canción en liras, aunque no está marcado como tal en ninguna de las ediciones, tiene su modelo en la Canción V en liras de Garcilaso, «Si de mi baja lira / tanto

\footnotetext{
5 Russell P. SEBOLD, Lírica y poética en España, 1536-1870, Madrid, Cátedra, 2003, pp. 23-46. Véase Juan Boscán, Obra completa, ed. de Carlos Clavería, Letras Hispánicas, 453, Madrid, Cátedra, pp. 395 y 118 respectivamente.

6 Garcilaso de la Vega, Obras [ed. de José Nicolás de Azara], Madrid, Imprenta Real de la Gaceta, 1765, prólogo sin paginar [p. XIV].

7 En Alberto PORQueras MAYO, El prólogo en el manierismo y barroco españoles, Madrid, C.S.I.C., 1968, p. 239.

${ }^{8}$ Citado por Ramón MEnÉndez PIDAL, Historia de la lengua española, Madrid, Fundación Ramón Menéndez Pidal, Real Academia Española, 2005, t. I, p. 1.145.

9 Garcilaso de la Vega, Obra poética, ed. de Morros, p. 12.

10 Ibid., p. 63.
} 
pudiese el son .... ${ }^{11}$. (Nótese de paso el adjetivo que Garcilaso aplica a su lira, pues lo veremos usar de modo semejante en el verso de Acuña.) $\mathrm{Y}$ es inolvidable la composición humorística de Acuña $A$ un buen caballero, $y$ mal poeta, la lira de Garcilaso contrahecha (322-325). De esta graciosa sátira veamos un par de estrofas.

Yo en ásperas montañas, no dudo que tal canto endureciese

las fieras alimañas,

o a risa las moviese

si natura el reír les concediese.

Y cuanto habéis cantado

es para echar las aves de su nido,

y el fiero Marte airado,

mirándoos, se ha reído

de veros tras Apolo andar perdido.

$[\ldots]$

Mas ¡ay, señor, de aquella

cuya beldad de vos fuere cantada!, que vos daréis con ella

do verse sepultada

tuviese por mejor que ser loada ${ }^{12}$

Otro documento que revela a un Hernando de Acuña estudioso de las dos tradiciones clásicas, es un poema latino atribuido a Garcilaso de la Vega y dirigido a Hernando, aceptado por los editores antiguos de Garcilaso, pero rechazado por algunos de los modernos: se trata del epigrama Garciae Lasi de la Vega ad Ferdinandum de Acuña ${ }^{13}$. Díaz Larios (14-15) explica cómo el poeta soldado novel pudo conocer al consagrado, al coincidir los dos en el servicio de Carlos V, en 1536. Tampoco a mí me parece que haya motivo alguno de rechazar este poema latino. Tanto Acuña como Garcilaso tuvieron cierta relación de amistad con Carlos V; y dadas estas circunstancias, sin que el epigrama fuese de Garcilaso, no parece en absoluto verosímil

${ }^{11}$ Ibíd., pp. 84-91.

${ }^{12}$ El buen caballero y mal poeta, objeto de la sátira de Acuña, es uno de dos traductores del Orlando furioso, de Ariosto: Jerónimo de Urrea, o bien Luis Zapata. Mas en aquél existe a la vez otro motivo tentador: dos años después que Acuña había publicado su versión de El caballero determinado, de Olivier de la Marche, en quintillas dobles o coplas reales, Urrea sacó su nueva traducción de esta obra en 1555, realizada en tercetos. Véase la Introducción de Díaz Larios, pp. 40-41.

${ }^{13}$ Entre las ediciones de Garcilaso que se hallan a mano, en mi despacho, este epigrama se halla recogido en la ya citada de Madrid, 1765, p. 188; en la de la Librería de Sancha, Madrid, 1821, p. 210; y en la de Antonio Gallego Morell, Garcilaso de la Vega y sus comentaristas, Granada, Universidad de Granada, 1966, p. 231. Luis F. Díaz Larios, editor del texto de Acuña que manejamos, reproduce el epigrama latino en la nota 9 de su Introducción (15). 
que un caballero tan honrado y decente en todos los aspectos como Hernando antepusiera el referido epigrama al texto de su traducción castellana de Le chevalier délibéré, de Olivier de la Marche, que él hizo a petición del Emperador. He aquí, en fin, el epigrama latino de Garcilaso:

\section{GARCIAE LASI DE LA VEGA AD FERDINANDUM DE ACUÑA}

Dum Reges, Fernande, canis, dum Caesaris altam progeniem nostri, claraque facta ducum,

dum Hispana memoras fractas sub cuspide gentes, obstupuere homines, obstupuere dei.

Extollensque caput sacri de vertice Pindi, Calliope blandis vocibus haec retulit:

Macte, puer, gemina praecinctus tempora lauro, qui nova nunc Martis gloria solus eras;

haec tibi dat Bacchusque pater, dat Phoebus Apollo, nympharumque leves Castalidumque chori,

ut, quos divino celebrasti carmine Reges, teque simul curva qui canis alma lyra,

saepe legant, laudent, celebrent post fata nepotes: nullaque perpetuo nox fuget atra dies ${ }^{14}$.

Garcilaso mismo debió de poner estos versos en manos del Acuña de dieciocho años, y fácil es imaginarse la orgullosa inspiración que arrebataría al alma del joven Hernando al leerlos por vez primera ${ }^{15}$.

No es éste el lugar de hacer la historia de la primera generación de líricos neoclásicos del quinientos, mas para aclarar el contexto histórico de la figura a quien estudiamos, tomemos nota de los paralelos que se dan entre Acuña y otro poeta soldado, contemporáneo suyo, el sevillano Gutierre de Cetina (1514/1517-1557). Gutierre se inspiró en el famoso soneto X de

14 Traduzco: «Mientras cantabas a los reyes, Hernando, mientras cantabas la alta progenie de nuestro César y los claros hechos de sus capitanes, mientras recordabas a los pueblos vencidos por las armas españolas, se han maravillado los hombres, se han maravillado los dioses. Asomando la cabeza a la cumbre del sacro Pindo, esto con blanda voz decía Calíope: "Muy bien, muchacho, ceñidas ambas sienes con laurel, que ahora sólo eras nueva gloria de Marte; estos otros dones te los dan el padre Baco, Febo Apolo y los gentiles coros de ninfas y musas, para que, como tú celebraste a los reyes con tu divina poesía, al mismo tiempo, a ti, que cantas con la curva y alma lira, te lean a menudo los descendientes, te loen, te celebren, y la negra noche no ahuyente para siempre la luz de tus versos"».

${ }^{15} \mathrm{M}^{\mathrm{a}}$ Carmen Vaquero Serrano afirma que el autor del epigrama latino en alabanza de Acuña fue el hijo de Garcilaso, Garcilaso de la Vega y Zúñiga (en Garcilaso, poeta del amor, caballero de la guerra, Madrid, Espasa Calpe, 2002, p. 316). Pero este hijo, nacido en 1527, no tenía sino nueve años en el momento en que Hernando parece haber recibido el epigrama; y aun suponiendo que el hijo de Garcilaso se lo hubiera dado en una fecha posterior, no parece verosímil que éste hubiera llamado puer, 'muchacho', a quien le llevaba nueve años. Además, el tono de todo el epigrama es de quien se refiere a un poeta novel y más joven. Quien escribe sólo puede ser el Garcilaso famoso. 
Garcilaso, «iOh dulces prendas, por mi mal halladas!», paradigma de la dulzura o blandura poética, para su propio soneto « $i A y$, dulce tiempo por mi mal pasado!» ${ }^{16}$. Pero a la vez que Cetina imitaba a un clásico español, creía ver renovada en su propia centuria la Edad de Oro de los grandes clásicos de Grecia y Roma. Es una visión que comparte con sus contemporáneos italianos, y la expresa traduciendo un soneto de Giraldi Cinthio. Son especialmente interesantes los tercetos de la versión de Cetina, donde el poeta alude a la elaboración de sus flores o poesías:

\footnotetext{
Que si algún tiempo con más docta mano las acierto a tejer como maestro, guardando a los pasados el decoro,

espero, y mi esperar no será en vano, que el nombre pastoral del siglo nuestro será tal cual fue ya en la Edad de Oro $^{17}$.
}

Del mismo modo, los neoclásicos del setecientos aspirarían a ver renovado en su siglo su muy admirado quinientos, «aquel buen tiempo de Garcilaso». En 1754, Luis José Velázquez compara los siglos XVI y XVIII viendo el primero como un «restablecimiento de las letras» con un nuevo «semblante», y el segundo como una «gran reforma» de las letras con «otro nuevo semblante» ${ }^{18}$. Y cada una de esas épocas de florecimiento neoclásico tenía una edad de oro hacia la que miraba en busca de inspiraciones para nuevos versos clásicos; pues el mismo crítico dieciochesco, Velázquez, fue quien puso al quinientos el bello nombre por el que todavía lo conocemos: dicho tiempo, decía, «fue el Siglo de Oro de la poesía castellana; siglo en que no podía dejar de florecer la buena poesía» ${ }^{19}$.

Las meditaciones de Acuña sobre la poesía clásica antigua y sobre la clásica moderna, que se iba elaborando en torno suyo, le llevaron a recordar la poética, esas indispensables reglas del buen poetizar, ese arte que pone a la naturaleza o inspiración espontánea en el escarpado camino recto al Parnaso. Sobre esto Acuña dirige a un poeta y amigo desconocido un soneto clave (XLIII), en cuyo primer cuarteto parece prever la tempestad barroca que había de desatarse sobre la lira, mientras que en las estrofas restantes abraza la poética clásica garcilasiana:

${ }^{16}$ Gutierre de Cetina, Sonetos y madrigales completos, ed. de Begoña López Bueno, Letras Hispánicas, 146, Madrid, Cátedra, 1981, p. 150. Estudio este soneto, junto con otras imitaciones del soneto X de Garcilaso, en mi artículo «La dulzura de Garcilaso y sus imitadores» [Cetina, Gerardo Lobo, Cadalso y Díaz de Goveo], en Salina, núm. 18 (noviembre 2004), pp. 119-125.

17 Ibíd., p. 78.

${ }^{18}$ Luis José VelázQuez, Orígenes de la poesía castellana, Málaga, Oficina de Francisco Martínez de Aguilar, 1754, pp. 57, 73.

19 Ibid., p. 66. 
Contra la ciega y general dolencia de la triste ignorancia miserable, que de común se ha hecho comportable, siendo tan insufrible pestilencia,

quiero que valga en esto mi sentencia, que vuestro dulce estilo tan loable os hará en Helicona memorable sin contraste ninguno, o diferencia.

Ya vuestro claro ingenio nos lo muestra, y ya el fruto gentil que dél procede a la cumbre del monte os encamina,

do subís sin errar por la vía diestra, camino que a tan pocos se concede, que ya por nuestro mal no se camina. (261)

Aparte del valor ornamental de las alusiones a los mitos antiguos en torno a la poesía, algunos de los nombres asociados con esas historias resultan cómodos como símbolos de aspiraciones y procesos poéticos. Con el difícil acceso a las alturas del Parnaso, la Helicona o el Helicón, se metaforiza la lucha del poeta con el estilo por lograr versos claros, fáciles y amenos de leer. El equivalente estilístico de vencer la altura de Helicona era la llamada dificultad vencida del estilo pulido, claro, clásico, o como también se decía, la facilidad difícil de ese estilo, fácil para el lector, difícil para el poeta porque esa sencilla amenidad sólo se logra pasándoles infinitas veces a los versos la exigente lima de Horacio. En su soneto, Acuña insiste tres veces en la idea de la dificultad vencida: 1) Helicona; 2) cumbre del monte; y 3) do subís.

La fuente doctrinal y estilística de este soneto es el segundo cuarteto del soneto XXIV de Garcilaso, donde el Príncipe de los Poetas Castellanos expresa su deuda con los poetas italianos que le inspiraron para que siguiera cultivando el endecasílabo y difundiera el modelo poético italiano por España. La aludida estrofa es:

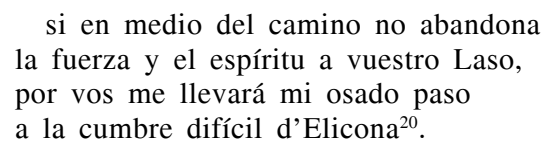

En estos versos queda claro el sentido alegórico de palabras como fuerza, espíritu y osado paso: se trata de la lucha del poeta con la lengua por conquistar la altura de la perfección a la que aspira, su Helicona personal. Mas nótese a la vez que en este soneto de Garcilaso, lo mismo que en el

${ }^{20}$ Garcilaso de la Vega, ed. de Morros, p. 45. 
de Acuña, la voz camino representa esa juiciosa poética clásica que tanto sostiene al que aspira a alcanzar la cumbre de Helicona.

Esto también es interesante a la vista de la premonición de la pestilencia culterana o barroca que hemos encontrado en el primer cuarteto del soneto XLIII de Acuña y que éste atribuye a la ignorancia, ignorancia del camino de la poética; porque en el siglo XVII los críticos garcilasistas recogerían la figura del camino y la idea de la ignorancia de la poética como explicación de la contaminación culterano-conceptista del añorado buen castellano. Así se expresa Antonio López de Vega, en su Heráclito y Demócrito, de 1641: «Tres son las sendas poéticas que hoy se siguen más comúnmente: la dramática, la lírica $\mathrm{y}$, aunque con menos secuaces, también la heroica. Casi todos los que van por ellas ignoran el camino» ${ }^{21}$. La situación concreta de los poetas líricos en su triste tiempo, López de Vega la describe así: «Por la senda de la lírica, que es la más común a los poetas de nuestro siglo, es tan copioso el número de los que caminan, que se atropellan unos a otros, y ésta debe de ser la causa porque casi todos se están en el mismo pasaje, ninguno o pocos pasan adelante» ${ }^{22}$.

Acuña tampoco ha dejado de meditar en otro principio de la poética horaciana que se sabían de memoria todos los líricos renacentistas: el consejo del poeta romano de que para el uso más eficaz de la lima se sometiera el borrador al juicio de un amigo imparcial y justo ${ }^{23}$. De la práctica de este precepto Acuña tenía en su modelo más admirado uno de los mejores ejemplos en los anales de la poesía: quiero decir, la amistad fraternal y relación literaria entre los poetas Boscán y Garcilaso. Y de este último poeta se trata en una de las ocasiones en que Hernando se acuerda de la valiosa práctica de consultar a los amigos sobre el estilo, pues es en la graciosa sátira $A$ un buen caballero, y mal poeta, la lira de Garcilaso contrahecha:

\footnotetext{
A vos es vuestro amigo

grave, si no os alaba, y enojoso,

y si verdad os digo,
}

${ }^{21}$ Antonio López DE VEGA, Heráclito y Demócrito de nuestro siglo, Madrid, Diego Díaz de la Carrera, 1641, pp. 173-174. La cursiva es mía. Sobre el estilo barroco visto por los espíritus garcilasistas del siglo XVII, véase el capítulo segundo, "“Palabras horrendas y vastas como elefantes": neoclasicismo frente a barroquismo», de mi ya citado libro Lírica y poética en España, 1536-1870, pp. 47-75. Otra voz usada en el soneto de Acuña que comentamos, pestilencia, también la utilizan los críticos seiscentistas del estilo barroco, y el nombre concreto de la pestilencia que infecta a los cultiparlantes es la elefancía, según Juan DE JÁUREgui, Discurso poético, ed. de Antonio Pérez Gómez, Opúsculos Literarios Rarísimos, Valencia, Duque y Marqués, 1957, p. 92.

${ }^{22}$ Ibíd., p. 178. La cursiva es mía.

${ }^{23}$ Puede consultarse el apartado 5, «La lima de Horacio, la podadera y el cincel», del capítulo XIV, «Las reglas universales del proceso creativo», de mi libro Lírica y poética en España, 1536-1870, pp. 450-463. 


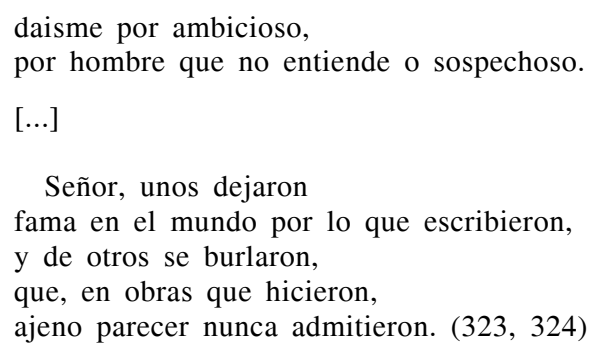

En su ensayo sobre Tres poetas clásicos (Garcilaso de la Vega, fray Luis de León y san Juan de la Cruz), Luis Cernuda escribe, en 1941: «Tan acendrada puede ser esa cualidad del estilo, que, a través de las obras donde existe, nos llega el hálito mismo de la época a que pertenecen aquéllas» ${ }^{24}$. Ahora bien, en el caso de Garcilaso, fray Luis y el santo y poeta carmelita, esa cualidad de la locución que representa el hálito de su época es «el estilo de clara sencillez que impera en el siglo XVI», por citar la opinión de Menéndez Pidal ${ }^{25}$. Por muchos cultismos y galas que incorporen a su estilo los poetas elegantes y los prosistas eruditos de ese tiempo, no desdeñan el espíritu del léxico y sintaxis populares. En Boscán, Garcilaso, Diego Hurtado de Mendoza, Cristóbal de Castillejo, Antonio de Guevara, los hermanos Valdés, Gutierre de Cetina, el autor del Lazarillo de Tormes, fray Luis de Granada, fray Luis de León, san Juan de la Cruz, santa Teresa de Jesús... y Cervantes, se descubre una común base expresiva que es esa llaneza que los une a todos en la comunidad del buen castellano; y es una llaneza tan libre de contaminaciones, que se toma fácilmente por la sencilla y limada locución del clasicismo más depurado.

Es este estilo sencillo y llano, por ejemplo, que Garcilaso usa en su cariñosa espístola dirigida a Boscán. Con tan amado amigo, dice Garcilaso, «ni será menester buscar estilo / presto, distinto, d'ornamento puro, / tal cual a culta epístola conviene $»^{26}$. Y fray Luis de León confirma la envidiable modalidad estilística de su centuria al censurar a los que criticaban las irregularidades del español escrito de Teresa de Ávila, «porque si entendieran bien el castellano, vieran que el de la madre es la misma elegancia $\gg^{27}$. Recordemos que según Pedro de Valencia lo que más falta le hacía a Góngora era cierta medida de llaneza. Condición esencial de esa coincidencia entre llaneza y clasicismo que había olvidado el segundo Góngora era la humildad.

La vivencia esencial de la llaneza en la literatura quinientista participa

${ }^{24}$ Luis Cernuda, Prosa completa, ed. de Derek Harris y Luis Maristany, Barcelona, Barral Editores, 1975 p. 748

${ }^{25}$ MenÉndez PIDAL, Historia de la lengua española, t. I, p. 909.

${ }^{26}$ Garcilaso de la Vega, ed. de Morros, p. 115.

${ }^{27}$ Citado por Menéndez Pidal, Historia de la lengua española, t. I, p. 903. 
del sentimiento de lo sublime. Hablando con la «ilustre y hermosísima María» a quien se dirige en su égloga III, Garcilaso ruega: «no te ofenda ni te harte / tratar del campo y soledad que amaste, / ni desdeñes aquesta inculta parte / de mi estilo, qu'en algo ya estimaste» (vv. 33-36) ${ }^{28}$. En la octava siguiente, Garcilaso vuelve sobre el mismo aspecto de su estilo, usando un sinónimo de llano frecuente en los poetas de su centuria, quiero decir bajo:

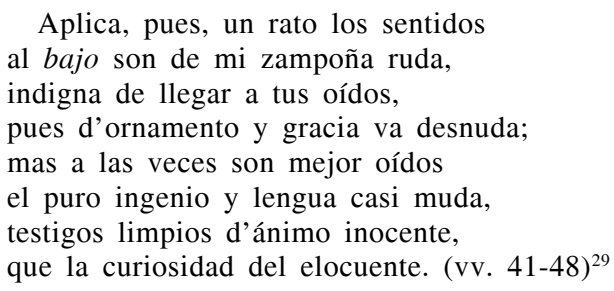

Soberano objeto de la admiración estética y el deseo amoroso, como esa ilustre María, frente al estilo inculto, bajo, rudo, ¿cómo mejor expresar el asombro ante ella y halagarla que con esa misma humildad con que nos situamos ante una sublime fuerza de la naturaleza? En otros textos, el tono humilde, bajo, llano se asocia a otra emoción igualmente frecuente en Garcilaso y los poetas de su tiempo: la dulzura. En una digresión de su égloga II, Garcilaso describe el carácter que Boscán, ayo de Fernando, el futuro tercer duque de Alba, había amoldado en este joven: «su ánimo formando en luenga usanza, / el trato, la criatura y gentileza, / la dulzura y llaneza acomodada, / la virtud apartada y generosa» (vv. 1341-1343) ${ }^{30}$. También en versos de Acuña veremos asociarse la llaneza a un gran personaje, una figura sublime. Mas miremos antes otro ejemplo en la obra de Garcilaso.

La primera lira de la Canción V, Ode ad florem Gnidi, de Garcilaso, contiene tanto una referencia a su humilde melodía como otra a encarnaciones de lo sublime, cual fuertes vientos y la furia del mar.

Si de mi baja lira

tanto pudiese el son, que en un momento

aplacase la ira

del animoso viento

y la furia del mar y el movimiento ${ }^{31}$.

Describir un autor su estilo uniendo un tono humilde, ya con objetos sublimes, ya con la dulzura, es señal de que aspira a esa mayor de todas las elegancias, que sin ostentar ninguna pretensión exterior, revela su gusto

\footnotetext{
${ }^{28}$ Garcilaso, ed. de Morros, p. 225.

${ }^{29}$ Ibíd., 226. La cursiva es mía.

${ }^{30}$ Ibíd., p. 201. La cursiva es mía.

${ }^{31}$ Ibíd., p. 84. Las cursivas son mías.
} 
superior por su sorprendente sencillez, o aun por su aparente despreocupación de toda cuestión de ornamentos.

Varios estudiosos de la poesía de Acuña han afirmado que cuando su viuda publicó sus poemas inéditos en 1591, once años tras su muerte, los juntó, fuese como fuese, sin preocuparse en absoluto por el orden de las piezas. Volveremos sobre esta cuestión, porque es importante. Pero creo que la viuda de Acuña, doña Juana de Zúñiga, o quien la ayudase a preparar el original para la madrileña Imprenta de P. Madrigal, entendía con cierta profundidad la estética del poeta soldado, así como la lógica del orden en que había dejado sus poemas. Para empezar, en los tres primeros poemas de la colección se expone la poética de Acuña, aplicándola a los contextos personal, patriótico y amoroso, y a lo largo del resto de su poemario el admirador de Garcilaso seguirá fiel a esos esquemas. Se trata de una estética cuyo carácter viene sugiriéndose ya en nuestras páginas anteriores.

El primero y más importante de los aludidos tres poemas iniciales es el soneto siguiente:

Huir procuro el encarecimiento, no quiero que en mis versos haya engaño, sino que muestren mi dolor tamaño cual le siente en efeto el sentimiento.

Que mostrándole tal cual yo le siento será tan nuevo al mundo y tan extraño, que la memoria sola de mi daño a muchos pondrá aviso y escarmiento.

Así, leyendo o siéndoles contadas mis pasiones, podrán luego apartarse de seguir el error de mis pisadas

y a más seguro puerto enderezarse, do puedan con sus naves despalmadas en la tormenta deste mar salvarse. (89; cursivas mías)

Huir el encarecimiento y mostrar su dolorido sentir cual él mismo lo siente es lo mismo que decirlo todo con la mayor llaneza, o sea con «mi bajo decir», según escribirá Acuña en otro soneto (278), recordando el sintagma «mi baja lira» de Garcilaso. He dicho que en el quinientos la vivencia de la llaneza participa a menudo de la sensación de la sublimidad. En las cortes y en los ejércitos confesar sin ambages lo más íntimo, como se proponía hacerlo Acuña, era una novedad tan singular, tan «extraña», que debía de dejar tan pasmadas a las gentes como hallarse de súbito ante un imponente pico u otra maravilla de la naturaleza. En esta primera composición alude Acuña también a otra destacada característica de su arte: con ser lírica su poesía, es la de quien a la vez se revela como un narrador nato. «Siéndoles contadas / mis pasiones», los lectores van a reaccio- 
nar psicológicamente, y de ahí nuestra inconfundible sensación de hallarnos en la presencia del cordial y fuerte yo del poeta. Al mismo tiempo, el cuento bien hecho deja prendido al lector, y de esta táctica veremos muestras más adelante. (El lector habrá notado que con la lección estética de este soneto se entreteje otra moral, aunque de menos interés para el estudioso de la lírica.)

El segundo poema de la colección y el segundo de los que vamos a analizar en la medida en que forman una codificación de la poética de Acuña, lleva el título A su Majestad y consta de dos octavas reales:

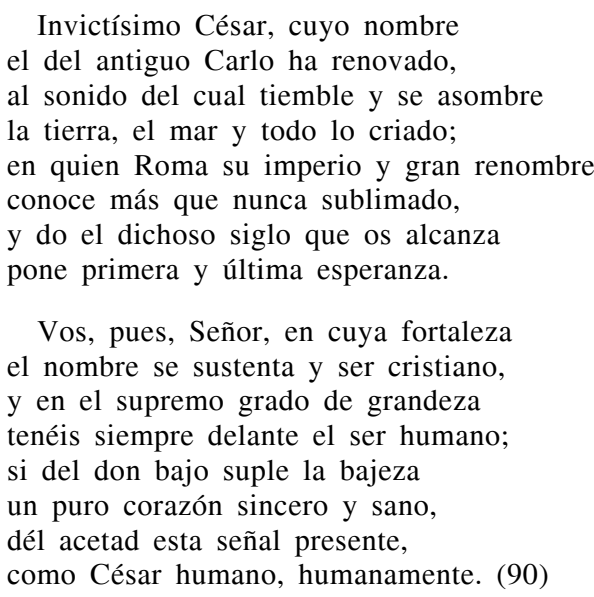

No es preciso comentar el evidente elemento de lo sublime en la primera octava, mas es una indispensable preparación para la dramática introducción contrastante del elemento de la llaneza en la segunda y para la comprensión de esa pareja de temas sólo en la apariencia contradictorios. Se precisa tener en cuenta que el César tan magníficamente apostrofado era un emperador joven que jugaba a la pelota con sus soldados y era el amigo de literatos y poetas como Castiglione, Navagero, Boscán, Garcilaso, Acuña y su extravagante bufón don Francés de Zúñiga, autor de la Crónica burlesca del Emperador Carlos V. Eco de semejante familiaridad es el tono con que Acuña se dirige a Carlos $\mathrm{V}$ y le aconseja en las páginas que añadió a la obra didáctica de Olivier de la Marche, Le Chevalier délibéré, al traducirla: «Debes te de levantar / de mañana diligente, / las narices atapar, / y la boca juntamente, / y así correr y saltar. / Aborrecer el dormir, / ser casto y vicios huir, / y ser sobrio en el comer, / y la lengua has de tener / moderada en el decir» ${ }^{32}$.

${ }^{32}$ El Cavallero determinado traduzido de lengua francesa en castellano por don Hernando de Acuña y dirigido al Emperador Don Carlos Quinto, Máximo Rey de Es- 
Pero volvamos a nuestro tema. De lo que se trata en este momento, en el verso de Acuña, es de jurar su lealtad a su Emperador y amigo, y aparecen una vez más los términos con que él y Garcilaso, antes que él, describían modestamente sus nada comunes talentos: bajo, bajeza. El sentido de estos versos es: si la humildad de mi humilde talento («don bajo») se compensa por la pureza, sinceridad y sanidad de mi corazón, aceptad estas octavas como testimonio de mi lealtad. Pero ¿cómo las ha de aceptar Carlos V? Pues como el compañero de ese juego de pelota, «como César humano, humanamente». El sintagma «César humano» casi parece oximorónico, mas cuando se considera con detenimiento, no es sino otro ejemplo de esa máxima elegancia que estriba en la mayor sencillez: «humanamente». En tales circunstancias no cabe palabra final más convincente. No cabe mayor majestad que la muy humana — la sublime- de Carlos V.

(En las octavas A su Majestad, queda expuesta a la vez la estética que llevará a la composición del poema más famoso de Acuña: el soneto $\mathrm{Al}$ Rey Nuestro Señor, que contiene ese sublime verso: «un Monarca, un Imperio y una Espada» [328], el cual es un curioso antecedente, si bien no la inspiración directa, del famoso lema de Luis XIV: «Un Roi, une Foi, une Loi».)

Al comienzo de La fábula de Narciso, la tercera composición contenida en Varias poesías, Acuña habla con la distinguida dama de sus pensamientos, Galatea por nombre poético, o sea doña María de Aragón, esposa de don Alfonso de Ávalos, marqués del Vasto. En la primera octava real de La fábula de Narciso, Acuña retorna al dramático contraste entre expresión «baja» y tema sublime con el fin de dar realce a su dama. Alude otra vez también a su atracción hacia la narrativa.

\author{
Si un bajo estilo y torpe entendimiento \\ merecieran llegar a aquella altura \\ do, señora, llegó mi pensamiento, \\ y tuviera en esto igual ventura, \\ pudiera yo contar lo que es sin cuento, \\ dando a vuestro valor y hermosura \\ seguridad, cual nadie la ha tenido, \\ de la ofensa del tiempo y del olvido. (91; cursivas mías)
}

paña, Nuestro Señor, Barcelona, en casa de Claudio Bornat, al Águila Fuerte, 1565, fol. 107. Cito por la edición facsimilar de la de 1565, Toledo, Antonio Pareja, Editor, 2000. La primera edición de la traducción de Acuña se estampó en Amberes en 1553. El mismo Carlos V tradujo la obra de Olivier de la Marche al castellano, pero en prosa, y pidió a Acuña que vertiera ésta en verso, pues el original francés se había compuesto en verso, con cuya ocasión el poeta amigo del Emperador interpoló estrofas nuevas y añadió otras al final. El Cavallero determinado tuvo siete ediciones en el siglo XVI, las dos primeras y la última en Amberes, y las restantes en España. Un poco más adelante en el texto que citábamos, Acuña pone esta aclaración: «Significa el atapar / las narices y la boca / que no ha de oler ni gustar / cuanto en vanidades toca / quien victoria ha de esperar» (fol. 108). 
Con la voz altura el poeta insinúa que la distinción de la dama es como una de esas levantadas eminencias de la tierra que asombran; idea que se encarece con la llegada a esas encumbradas regiones del pensamiento, cuyos vuelos no conocen límite. Un torpe entendimiento, aun cuando de hecho existiera en Acuña, no excluiría la posibilidad de existir también en él una viva imaginación; y en esta ocasión lucha su imaginación, armada del estilo humilde, hasta vencer los obstáculos más difíciles que pueden concebirse con la idea de lo sublime: el tiempo y el olvido. Sobre el imperio romano, diría el poeta Gabriel Álvarez de Toledo (1662-1714): «Ni gastar puede el tiempo tu memoria, / ni tu ruina caber en el olvido» ${ }^{33}$. En el ritmo de los dos últimos endecasílabos de la octava se siente toda la fuerza de la aspiración de ese bajo pero hábil estilo a arribar a la sublimidad. En tal contexto incluso la alusión de Acuña a su talento de narrador se asocia a lo sublime, porque contará lo que es sin cuento.

Tan universal en la obra original de Acuña es el armonioso juego entre la bajeza y la sublimidad, que el poeta hasta parece haber escogido algunas de las obras que tradujo teniendo esta característica en cuenta. Verbigracia, en La contienda de Áyax Telamonio y de Ulises sobre las armas de Aquiles (152-177), en verso suelto, que excepto los treinta y siete primeros versos Acuña tradujo de Ovidio, el estilo humilde de Áyax y el retórico de Ulises forman un contraste parecido. Es sublime asimismo en no pocos versos la sencilla locución de Dido en la Carta de Dido a Eneas, en tercetos, traducida del mismo poeta romano, a cuyo final Acuña ha puesto, en un cuarteto de endecasílabos, el epitafio que la reina de Cartago se ha compuesto: «La causa desta muerte dio, y la espada, / el cruel capitán de los troyanos; / la triste Dido, de vivir cansada, / buscó descanso con sus propias manos» (225).

Antes de emprender el análisis de otros poemas, reunamos a lo largo de la obra poética de Acuña, como testimonio del papel clave del estilo llano renacentista en su verso, ejemplos adicionales de sus frecuentes referencias al que llama su «don bajo»: «nuestro pastoral estilo y llano» (124); «en forma pastoral, rústica y llana» (127); «como ser bajo estilo el de mis versos» (132); «mi rústica lira» (132); «en mi bajo estilo» (231); «pueda mi bajo estilo declararte» (301); «es vuelto en escabroso estilo y duro / el mío, que antes era humilde y llano» (318); «la torpeza / de mi tan rudo verso y $\tan \sin$ arte» (337).

Hace unos momentos, citamos un verso de Garcilaso en el que se unen la llaneza y la dulzura, y no sorprende que esto ocurra, porque la dulzura que más conmueve es la natural, la llana, la baja, la humilde y sin artifi-

${ }^{33}$ En el soneto A Roma destruida, en Poetas líricos del siglo XVIII, t. I, ed. de Leopoldo Augusto de Cueto, Biblioteca de Autores Españoles, 61, Madrid, Atlas, 1952, p. 5 a. 
cio. Por tanto, en algunos de los mismos poemas en que Acuña se refiere a su bajo estilo, también se refiere a la dulzura estilística. De vez en cuando se sustituye dulce por blando, sinónimo del primer calificativo en la terminología de la poética clásica y neoclásica (Garcilaso habla de «su blanda musa» $)^{34}$. Veamos varios ejemplos de estas otras referencias estilísticas de Acuña: «de un dulce estilo y de un sonoro canto» (124); «el blando estilo y amoroso» (235); «al son de un dulce estilo delicado» (257); «un estilo en cantar dulce y subido» (288).

Queda aludida la opinión de los estudiosos que ven el orden interior de la obra poética de Acuña como un caos absoluto ${ }^{35}$. No recuerdo a ningún lírico cuya obra esté caracterizada por un orden interior completamente lógico. Hay grandes poetas - Garcilaso, Bécquer- para cuyas composiciones los eruditos defienden órdenes enteramente diferentes entre sí. Y nunca se acabará de conocer el orden que debían tener los poemas de Juan Ramón Jiménez. Mas la disposición interior tradicional de las piezas poéticas de Acuña parece, por lo contrario, manifestar una lógica artística poco frecuente, así como cierto orden autobiográfico subjetivo, más bien que cronológico, el cual ya explicaré. Hemos hablado de la lógica colocación a la cabeza de toda su obra de los tres poemas en que Acuña diserta sobre su estilo, la sublime novedad de su sinceridad y el juego entre la llaneza y lo sublime que caracteriza a todas sus páginas.

Ahora bien: con igual lógica Hernando coloca en el cuarto lugar la primera de sus dos églogas, sobre cuyo contenido comenta el pastor Tirsi: «Hubo mil cosas, es un largo cuento» (121). Tan largo cuento es, en efecto, este poema, que al mismo tiempo dota de estructura poética a las composiciones restantes. Tan largo cuento es, que según dirá el poeta ciento ochenta páginas más adelante, hablando con su primera amante, Silvia: «De mi vida presente y la pasada / quedará para ti sabrosa historia / del alma por mi mano trasladada» (300). Largo cuento, historia del alma, dice Acuña que hay en sus versos, y podría muy bien haber dicho: Mis versos son la novela de mi vida, mi autobiografía lírica. Pues largo cuento, historia del alma, novela y autobiografía lírica son todos términos suficientemente abarcadores para nombrar todo cuanto cabe en unas doscientas sesenta y cinco páginas, en las categorías de narración, reflexión, temas principales, digresiones, saltos atrás, amistades, intereses momentáneos, diversiones li-

\footnotetext{
${ }^{34}$ Garcilaso, ed. de Morros, p. 87.

${ }_{35}$ Así, por ejemplo, Elena Catena, en su edición de hace medio siglo: «Por lo imperfecto de la colección no es aventurado suponer que doña Juana [de Zúñiga] debió de exhumar de algún viejo mueble, donde su marido las tendría en informe montón, toda clase de composiciones propias y ajenas, y darlas sin más revisión al impresor P. Madrigal, que siguió el mismo caótico sistema para editar el libro (en HERNANDO DE ACUÑA, Varias poesías, ed. de Elena Catena de Vindel, Biblioteca de Antiguos Autores Hispánicos, Madrid, C.S.I.C., 1954, pp. VIII-IX).
} 
terarias menores como la traducción ${ }^{36}$, etc. Adviértase al mismo tiempo que la primera égloga que Tirsi llama «largo cuento» viene a ser la Introducción a la novela lírica del conjunto de la obra de Acuña, porque en ella se exponen como en resumen y por adelantado casi todos los temas que se presentarán a lo largo del poemario.

En relación con la idea de la novela, novela de la vida de Acuña, escrita en primera persona, tomemos nota de una importante diferencia entre sus églogas y la primera y tercera de Garcilaso, por ejemplo, en las que dos pastores se quejan de sus amores no correspondidos y de la crueldad de sus idolatradas pastoras. En la única égloga de Hurtado de Mendoza también aparecen dos pastores que lamentan la mala inclinación de sendas amadas. En la primera égloga de Acuña, el poema IV de la colección, cn cambio, Damón, nombre poético del autor, es el único pastor que se siente herido por el cruel olvido de su bella divinidad humana; aspecto en el que se parece más esta composición a la segunda égloga de Garcilaso, en la que el único pastor y amante infeliz es el loco Albanio. Pero nada de loco tiene Damón; al contrario, es un varón fuerte, pastor, soldado y poeta, a quien admiran los pastores Tirsi y Fileno, con quienes dialoga. En la segunda égloga de Acuña (poema V), se quejan dos pastores de la indiferencia de sus amadas: Silvano se queja de la crueldad de Silvia, y Damón de la de Galatea. Mas se trata de un juego de espejos; pues Silvano es otro nombre poético de Acuña bajo el que amó a Silvia en otro tiempo, y con el nombre de Damón ama ahora a Galatea. Así simplemente se trata de un diálogo interior entre el Acuña de un momento y el de otro, y seguimos con una sola figura central, única posibilidad, dado el carácter de esta «sabrosa historia del alma».

Volvamos al poema IV, la primera égloga de Acuña, donde se inaugura su «largo cuento». El pastor Damón se halla recostado en la hierba de un prado cerca del Danubio, escuchando el dulce murmullo de una fuente; en una mano tiene su zampoña, y en la otra una pintura de Galatea, su «gran pastora» (115). «La vista, el arte y toda su manera / mostraba hombre de amor apasionado, / que teme todo mal y bien no espera» (116). La pasión de Damón (Acuña) y su aire desesperanzado fascinan a cuantos le topan, y su palabra no decepciona a quien le escucha, verbigracia, en su canto en sextinas

\footnotetext{
${ }^{36}$ La obra más extensa cuya traducción Acuña emprendió es el Orlando innamorato de Boiardo. Este proyecto, con el que se confirma el atractivo que la narrativa ejercía sobre Hernando, quedó inacabado, interrumpiéndose después de las seis primeras octavas reales del canto IV. No se incluye esta versión incompleta en la edición de las $V a$ rias poesías preparada por Díaz Larios. En las ediciones antiguas, el Orlando enamorado ocupa las páginas finales de los volúmenes de 1591, 1593 y 1804, indicándose así tal vez que se trata del último proyecto al que se dedicaba Acuña. Para su texto consulté la edición neoclásica de Madrid, Imprenta de Sancha, 1804, pp. 237-311.
} 
Tiempo fue ya que de amorosos versos hice yo resonar algunos campos como éstos baño agora con mi llanto, agora que hay en medio cien mil tierras desde mis ojos hasta Galatea, en cuya vista sola está mi vida.

Mas mientras el cielo me concede vida, y a mi canto la voz, siempre en mis versos el nombre sonará de Galatea por montes, por riberas y por campos, y llegará a las más extrañas tierras la alta ocasión de mi continuo llanto. (131-132)

«La soltura y desdén, la gallardía, / la verde juventud y el dulce canto» (119) de Damón atraen especialmente a Tirsi y Fileno. Estos pastores son el público de Damón, pues si Acuña es un narrador nato, su álter ego pastoril es un actor nato. El término público lo preveía el poeta en su ya comentado primer soneto donde suponía que «siéndoles contadas / mis pasiones», reaccionarían vivamente los oyentes, quizá escarmentando por ellas. En el Canto de Silvano, uno de los saltos atrás de este cuento o novela autobiográfica, según ya explicaré, Acuña representa de modo más completo lo que es un público de pastores: «Y de las dos riberas [del Tesín o Ticino] se juntaba / la más sentida parte de pastores, / que, estimando mi canto, me escuchaban» (291). Todo creador literario metamorfosea su materia prima al incorporarla a su simulacro de la vida, y ¿cómo no sospechar que el original de este público de pastores habrá sido un público de soldados, sentados en torno al fuego, escuchando ávidos la entretenida relación de los amores de su compañero Acuña? Nótese que de las tribus del Tesín los pastores que venían a escuchar a Silvano eran «la más sentida parte». Gente del mismo gusto que vamos descubriendo en Tirsi y Fileno.

La fascinación de estos sencillos pastores se entiende porque su compañero, nuevamente retirado a la vida pastoril, ha tenido mucha más experiencia de vida, de mundo y de literatura que ellos. Dice Tirsi:

Era su fundamento honroso celo $\mathrm{y}$, siguiendo de Marte el ejercicio con el ardiente sol y el crudo yelo,

se aplicó de tal suerte al duro oficio que en él y en todo siempre se ha mostrado sujeto a la virtud, libre de vicio.

Y, con seguir este arte, no ha olvidado la de Apolo y las musas, ni se olvida del trato pastoral ni del ganado. (119)

Emocionado, Fileno le implora a Tirsi: «Dime toda su historia, por tu vida» (120). 
Riberas del Danubio, se queja lloroso Damón de la ausencia de Galatea, mas antes en Italia, riberas del Tesín, cuenta Tirsi, el mismo Damón

Su Silvia, sin cesar, siempre cantaba, de Silvia eran sus tratos y porfías, y Silvano por Silvia se llamaba.

Duróle esta pasión no pocos días, hasta que el tiempo y otras ocasiones la fueron deshaciendo por mil vías.

Mas si perdió pasión, cobró pasiones presto su corazón, que son bastantes a deshacer mil fuertes corazones. (120-121)

He aquí, en los versos que acábanse de citar, la introducción del ya aludido salto atrás relativo a los amores antiguos de Acuña/Silvano/Damón con Silvia, al parecer el más obsesionante de sus amores, no solamente porque le dedica más poemas a ella, sino porque los dedicados a la pastora del Tesín son más apasionados y se los dedica ya algún tiempo después de concluidos esos amores.

Los poemas a los que me refiero son la segunda Égloga y contienda entre dos pastores enamorados sobre cuál dellos padece más pena: Silvano, que habiendo dicho la suya, es maltratado; o Damón, que no la osa decir (140-151), en verso suelto; un soneto sin título sobre Silvia y Silvano (249); Silvano a su pastora Silvia, soneto (287); Canto de Silvano, en tercetos (288-295); un soneto sin título, sobre la «grave enfermedad» de Silvia (296); Silvano a Silvia, carta en tercetos (297-301); un soneto sin título, sobre la crueldad de Silvia (302); otro sobre Silvia y Silvano sin título (310). Éstos son los saltos atrás que en diferentes momentos interrumpen el presente de la novela autobiográfica del conjunto de la obra poética de Acuña, pero que como otros temas principales de Varias poesías se anticipan en esa versión abreviada de su novela autobiográfica que es su primera égloga (115-139). Tirsi es amigo de Damón desde hace tiempo, y es de suponer que aquél habrá contado a Fileno la sustancia del contenido de las composiciones dedicadas a Silvia; y los antiguos amores de Damón, junto con sus conmovedores apóstrofes a la Galatea ausente, que Fileno escucha, tienen a este inocente pastor completamente embelesado.

La reacción de Fileno es como la del lector enganchado: «Cuantas cosas me cuentas de una en una - le confiesa a Tirsi, antes de haber escuchado a Damón - / me tienen espantado, y me parece / extraña y memorable cada una» (129). Más abajo, en la misma página, el ansioso Fileno no controla ya su curiosidad: «Pero lo que deseo, si ser pudiese, / es verle cantar solo sus amores / y poderle escuchar sin que él me viese». Poca diferencia hay entre la actitud de Fileno y la de uno de nuestros rockeros actuales ante su ídolo musical. Tras haber escuchado el ya citado canto de 
Damón, Fileno vuelve a ello: «Tiénesme, Tirsi, ya tan deseoso / de ver a ese pastor y de hablalle, / que hasta cumplillo no tendré reposo» (135). Hablan con Damón, y aun el más contenido Tirsi parece haberse contagiado de la fascinación de Fileno, al dirigirse así al amante de Galatea: «Ya tu mal es común, que entre pastores / a muchos tiene tristes tu tristeza / y dan dolor a muchos tus dolores» (136).

La anhelante admiración de Fileno tenía que halagar a Damón, pero le ha afectado aun más profundamente lo dicho por Tirsi: «Tirsi — le responde-, la voluntad que he conocido / en ti de tanto tiempo me asegura / que te duele mi mal y te ha dolido» (ibíd.). Por los mismos años, decía compasivo Lázaro de Tormes: «Sentí lo que sentía», al observar a su tercer amo, el malhadado y hambriento escudero ${ }^{37}$. Una simpatía anímica como la de los tres pastores de Acuña es muchas veces la base de una hermosa amistad, y este tema lo trata también Acuña en un soneto dirigido al parecer a Martín Cortés, hijo del conquistador: «Si a decirte verdad soy obligado, / don Martín, pues sé bien la de tu pecho / y estás de mi amistad tan satisfecho / cuanto yo de la tuya confiado, / te amonesto que...» (329).

Este último tema, tratado unas doscientas páginas después de la primera égloga, está así como anunciado en el «largo cuento» que sirve de Introducción a la más larga novela de la vida de Acuña. Y el lector recordará que otros temas, tratados a lo largo de la obra de Acuña, cual el militar, el literario, el de Galatea, el de Silvia y el de la personalidad del poeta, se hallan anunciados de la misma forma en el «largo cuento» prologal. Mas el tema central, el que más nos capta en todo poeta lírico es el de su propia psique; y el mayor interés de los temas restantes es su papel de vías de acceso a la personalidad del poeta.

Existe una alternativa del extenso y detallado examen temático de todos los poemas de Hernando para conocer cómo su sensibilidad nos llega a través de versos dedicados a todos los asuntos. He hablado en varias ocasiones de lo que llamo versos autónomos ${ }^{38}$. Un verso autónomo es el que leído solo, completamente separado de su contexto, provoca sin embargo esta reacción: Pero esto sí que es poesía, poesía auténtica, pues se unen en estas ocho, once, doce o catorce sílabas lo selecto de sus voces, el orden sugerente de éstas, el delicioso ritmo de sus sílabas, el vago rastro de un tema, algo de movimiento narrativo y la sensibilidad del poeta que lo concibió. Leer debida y plenamente un verso autónomo es fundir nuestro espíritu con el del poeta, sentir ese momento fugaz, «cual le siente en efeto el sentimiento», cual lo siente Fileno, cual lo siente Tirsi, en fin, vivir

${ }^{37}$ Lazarillo de Tormes, ed. de Francisco Rico, Letras Hispánicas, 44, Madrid, Cátedra, 1987, p. 89.

${ }^{38}$ Véase, por ejemplo, «Interián de Ayala en el neoclasicismo español», en mi libro El rapto de la mente. Poética y poesía dieciochescas, $2^{\mathrm{a}}$ ed., Barcelona, Anthropos, 1989, pp. 203-220. 
algo espontáneo e íntimo, no totalmente diferente de la primera emoción de un nuevo afecto. La vivencia de un verso autónomo nos introduce en la compañía íntima del poeta. La presencia de versos autónomos en los textos de un poeta es uno de los criterios más seguros de su calidad.

Voy a poner aquí una breve antología de los versos autónomos de Hernando de Acuña:

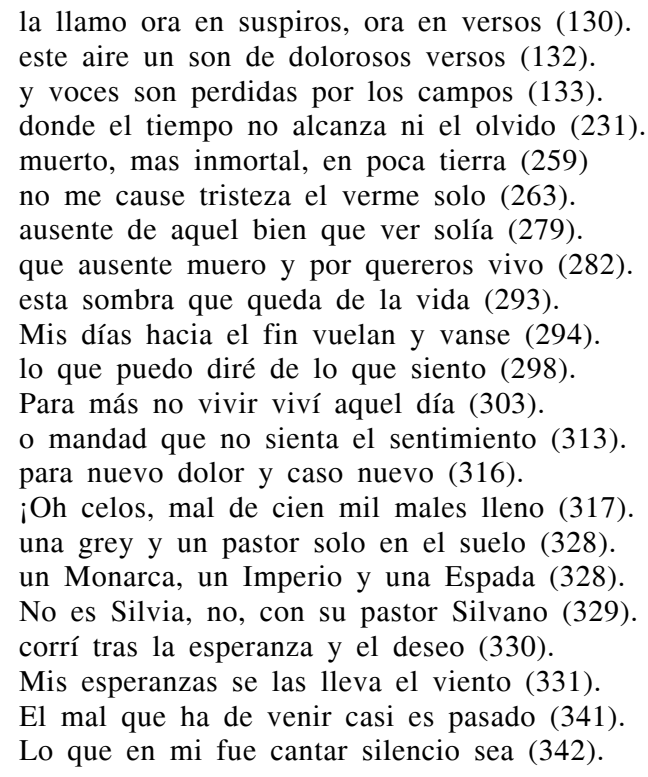

En la obra de Acuña existen también grupos de dos y tres versos que tienen algunas de las características de los versos autónomos, y son a la par brevísimas codificaciones de los principios poéticos que hemos deslindado. En una ocasión, Acuña justifica la forma de sus versos, «no porque vayan guarnecidos de arte, / sino por ser el cuento simple y puro» (294; cursiva mía). El poeta busca aquí una adecuación entre el estilo sencillo y la materia sencilla de su existencia, que llama cuento, cuento simple, cosa que gentes modestas podían contarse. Frente a los riesgos Acuña es fiel a sus principios heroicos y literarios; «que sé que a cada paso de este cuento / he de topar mil veces con mi muerte» (298; cursiva mía).

En los versos autónomos hemos detectado algo de movimiento narrativo, y en las dos últimas citas vuelve a aparecer el sustantivo cuento. Es una constante del crear poético de Acuña la visión narrativa de las cosas, porque no se le olvida en ninguna página que se está escribiendo la «sabrosa historia / del alma por mi mano trasladada» (300). Como reconfirmación de su constancia en el cometido de narrador, parece apropiado dejar aquí, al final de nuestra pesquisa, una breve recopilación de ejemplos adi- 
cionales, no citados anteriormente, de su preocupación por la veta narrativa de su labor poética: «en vuestro nombre trataré una historia / cuyo sujeto no se finge en vano» (92); «si nunca le conté mi desventura» (99); «y, con manera de hablar graciosa, / tanto la [entre]tuvo en un sabroso cuento, / que la diosa tardó y erró su intento» (101); «como en suma, Fileno, te he contado» (134); «un pensamiento / que me renueva el doloroso cuento / de mi estado presente y del pasado» (253); «excede / tan claro la materia toda historia» (278); «Pues no ha querido la ventura mía / que os pudiera contar lo que he pasado» (279); «Con esta simple pastoral historia / procuraba dejar en estos llanos / inmortal para siempre tu memoria» (291); «Temo contar mi dolorosa suerte» (298). He escrito las palabras clave en cursiva. Estas muestras vienen de poemas largos, de poemas breves como sonetos y de alguna de las traducciones de Acuña, donde por su constante preocupación narrativa usa la misma terminología.

Es simpático el autor de Varias poesías, y es palpable su sinceridad y honradez. A lo largo de sus páginas muestra siempre su experiencia de las cosas y su dolor, «cual le sienta en efeto el sentimiento». Leamos el segundo terceto de la carta de Silvano a Silvia: «Yo quisiera hacerte, si pudiera, / esta mi carta alegre o menos triste, / mas salióme por fuerza verdadera» (297). De un caballero igualmente honrado, virtuoso y discreto recibió el modesto Acuña un soneto en que aquél le elogiaba mucho, y al responder con otro soneto tacha el primer poema por un solo defecto, «y es que a un alto decir se requería / igual con las palabras el sujeto» (303).

Hernando de Acuña es un hombre renacentista: cree en el derecho divino de su Emperador, cree en la ética de la caballería, cree en la fuerza desnuda de su propio brazo, cree en el honor de servir largos años a Carlos V y Felipe II, en la guerra, en la diplomacia, en la prisión francesa y en la paz; y durante todos esos años — dice- «serví siempre a mi costa, sin gajes ni otro entretenimiento, y así quedé siempre olvidado y sin tener con que vivir». Sólo al final de su vida, pensando en su esposa, Hernando suplica a Felipe II tenga la bondad de «mandar se recompense algo a doña Juana, a la cual dejo encargada mi alma» ${ }^{39}$.

Era Acuña y había sido desde sus dieciocho años valeroso defensor de España; y junto con su Emperador, el marqués de Ávalos y otros nobles y esforzados caballeros, era en Italia y Alemania forjador de nuevos reinos y nuevas alianzas. Era soldado, vivía en este mundo. Era un buen cristiano, mas no tenía los ojos puestos en la región trascendente. Concluyó el Concilio de Trento diecisiete años antes de su óbito, acaecido probablemente en 1580, mas por su forma de ser no le afectó profundamente la nueva cosmovisión tensa, conflictiva, ascética de la Contrarreforma, que empeza-

${ }^{39}$ Memorial de don Hernando de Acuña a Felipe II, en Acuña, Varias poesías, ed. de Antonio Vilanova, Barcelona, Selecciones Bibliófilas, 1954, pp. 28-29. 
ba a colorarlo todo y a la larga influiría sobre los inquietos y paradójicos estilos barrocos. Del angustiado claroscuro postridentino no se dan sino pasajeros reflejos en el verso de Acuña, que al final de sus días se preocupaba por el sustento de su viuda en este mundo antes que por la salud de su propia alma en el otro. Sólo rara vez se oye en su obra un eco del ambiente ascético contrarreformista:

$$
\begin{aligned}
& \text { y conoce que es viento, sombra o muerte } \\
& \text { cuanto el error del mundo llama vida. (327) }
\end{aligned}
$$

Más característico del bizarro soldado renacentista Hernando de Acuña es este otro trozo: «Sin temer el camino voy contando / los pasos por do a muerte voy derecho» (312). Hernando es un poeta en quien el lector solitario encuentra un amigo acogedor, cuyo hablar llano invita al reposo, a la meditación. 